\title{
IGUALDAD, ORIENTACIÓN SEXUAL Y JUICIO ESTRICTO DE PROPORCIONALIDAD. COMENTARIO A LA SENTENCIA DE LA CORTE INTERAMERICANA DE DERECHOS HUMANOS EN EL CASO ATAla RIFFO Y NIŃAS VS. CHILE, DE 24 DE FEBRERO DE 2012
}

\section{ESTEBAN SZMULEWICZ RAMÍREZ*}

\section{INTRODUCCIÓN}

Nuestro sistema constitucional consagra el principio de igualdad en varias de sus normas, destacando en su capítulo primero como base de la institucionalidad y en el capítulo tercero como el derecho a no ser discriminado arbitrariamente, ya sea por ley, por actos de cualquier autoridad, así como también por acciones de particulares. La Constitución admite el establecimiento de distinciones, siempre y cuando puedar ser consideradas razonables, es decir, que no afecten a un colectivo históricamente marginalizado y cuya representación en el proceso político ha sido tradicionalmente malograda. En caso de que se pretenda establecer una diferencia de trato vinculada a alguna de estas "categorías sospechosas", la autoridad se deberá sujetar a un juicio estricto de proporcionalidad, vale decir, que la medida tienda a cumplir una finalidad constitucionalmente deseable y que se verifiquen los tres subprincipios de proporcionalidad.

En este sentido, en el caso Atala una jueza formuló una denuncia en contra del Estado de Chile por cuanto la Corte Suprema le había otorgado la tuición de sus tres hijas al padre de estas en base a la homosexualidad de la madre. La Corte Interamericana de Derechos Humanos (Corte IDH), tribunal internacional encargado de resolver los conflictos sobre la interpretación y aplicación de la Convención Americana de Derechos Humanos $(\mathrm{CADH})$, estableció que la orientación sexual es una categoría protegida por la $\mathrm{CADH}$, por lo que las decisiones de los órganos del Estado no se pueden basar en esta consideración para fundar una distinción, a

\footnotetext{
Licenciado en Ciencias Jurídicas y Sociales por la Universidad Austral de Chile. Magíster en Ciencia Política por la Universidad Autónoma de Barcelona (España). Magíster en Política Comparada por la London School of Economics and Political Science (ReINo Unido). Profesor de Derecho Constitucional e Investigador del Centro de Estudios Constitucionales y Administrativos en la Universidad Mayor (CHILE) y Profesor de Derecho Constitucional en la Universidad Central, sede La Serena (CHILE). Correo electrónico: esteban.szmulewicz@ umayor.cl.

Este comentario contó con la colaboración de la ayudante de investigación del Centro de Estudios Constitucionales de la Universidad Mayor, Javiera Ramírez.
} 
menos que satisfagan un juicio estricto de proporcionalidad, lo que en el caso de la sentencia de la Corte Suprema de Chile no se cumple. La sentencia de la Corte IDH versa precisamente sobre estos puntos, al declarar, en lo esencial, que el Estado de Chile vulneró el derecho a la igualdad ante la ley, a la privacidad y a la familia, por haber discriminado en contra de la jueza Karen Atala en razón de su orientación homosexual.

Para analizar esta decisión, es útil comenzar por realizar un breve recuento del caso Atala en su fase nacional, para luego desarrollar brevemente el procedimiento ante la Comisión Interamericana de Derechos Humanos (CIDH). A continuación, se expondrán los principales fundamentos de la sentencia de la Corte IDH, para finalizar con algunos comentarios a dicha decisión.

\section{1) La SENTENCia de la CorTe Suprema}

Esta causa se origina en un recurso de queja en contra de los Ministros y el Fiscal Judicial de la Corte de Apelaciones de Temuco, por resolver, en segunda instancia, que la tuición de las hijas menores de edad era otorgada a la madre, Karen Atala. El padre de las menores, demandante de tuición y recurrente de queja, estimó que se había incurrido en graves faltas al haber otorgado la tuición de sus hijas a la madre, sin tener en consideración los derechos de las nińas, privilegiando los derechos de la madre y sin tener en consideración ciertas circunstancias que afectaban gravemente a las menores, específicamente lo que dice relación con el hecho de que al ponerse término a la vida conyugal, Karen Atala reconoció y asumió explícitamente su condición homosexual, conviviendo de esta manera con sus hijas y su pareja de sexo femenino.

La Cuarta Sala de la Corte Suprema para resolver este recurso se remitió a las normas contempladas en el Código Civil, específicamente a los artículos 224 y 225 que versan sobre los "Derechos y obligaciones entre los padres y los hijos" y el "cuidado personal de la crianza y educación de sus hijos", teniendo como principal eje el interés superior del niño, regulado en el artículo 222 del Código Civil y en los artículos 3 y 9 de la Convención Internacional sobre los Derechos del Niño. A pesar de que la normativa civil -artículo 225- establece que en caso de que los padres vivan separados, "el cuidado personal de los hijos toca a la madre", esta regla no es absoluta ni definitiva, pues se puede modificar "cuando el interés del hijo lo haga indispensable, sea por maltrato, descuido u otra causa calificada el juez podrá entregar su cuidado personal a otro de los padres". En esta línea, la Corte Suprema cuestionó el hecho de que "los jueces recurridos no consideraron debidamente los efectos que ella [la orientación homosexual de la madre] puede acarrear en el cabal resguardo de los 
intereses de las hijas y cometieron falta o abuso grave tanto al aplicar las normas legales que rigen la materia, como al apreciar los antecedentes de la causa en que pronunciaron la sentencia que ha originado el recurso".

El máximo tribunal nacional desestimó los informes periciales de diferentes psicólogos y asistentes sociales, aportados en el juicio de tuición de las menores, acerca de que la "condición de homosexual de la madre no vulneraría los derechos de sus hijas, ni la privaría de ejercer sus derechos de madre, pues se trata de una persona normal desde el punto de vista psicológico y psiquiátrico", esgrimiendo para tal efecto el testimonio de personas cercanas a las menores,"como son las empleadas de la casa, hacen referencia a juegos y actitudes de las niñas demostrativas de confusión ante la sexualidad materna que no han podido menos que percibir en la convivencia en el hogar con su nueva pareja". Este tipo de acciones puede causar -en opinión del tribunal- "la eventual confusión de roles sexuales", al tener la carencia en el hogar de un padre (sexo masculino) ya que en esta situación se entiende que esta figura estaría siendo remplazada por una persona del género femenino, lo que puede generar una "situación de riesgo para el desarrollo integral de las menores". Además, se encontrarían en un estado de vulnerabilidad en su medio social, pues se demuestra evidentemente que la situación familiar en que las menores se desenvuelven es excepcional a la que tienen sus amigos, compańeros de colegio y de vecindad, lo cual las expone a que sean "objeto de aislamiento y discriminación que igualmente afectará a su desarrollo personal". Finalmente, se estimó que se vulneraba el "derecho preferente" de las menores a vivir y criarse en una familia normal y tradicional.

En conclusión, a juicio de la Corte Suprema, las condiciones y circunstancias antes mencionadas califican dentro de las situaciones incluidas en el artículo 225 del Código Civil inciso tercero, que autorizan al juez a entregar el cuidado personal de los hijos al padre en aquellos caso en que la madre, en el ejercicio de este derecho, pueda incurrir en daños que "podrían tornarse irreversibles", procediendo a invalidar la sentencia de la Corte de Apelaciones de Temuco y el fallo de primer grado del 29 de octubre de 2003; declarándose de esta manera la tuición de sus hijas al padre.

En su voto en contra, sin embargo, los Ministros Benquis y Álvarez estuvieron por rechazar el recurso de queja, fundamentalmente por sostener que "en los dictámenes que obran en los autos agregados, tanto los sicólogos como las asistentes sociales, infieren que la homosexualidad de la madre no vulnera los derechos de las nińas, ni priva a aquella de ejercer su derecho de madre, ya que desde una perspectiva sicológica o siquiátrica, a juicio de dichos expertos, se trata de una persona absolutamente normal". 


\section{2) El PROCESO ANTE la COMISIÓN INTERAMERICANA DE DERECHOS HUMANOS}

A raíz de este fallo, la jueza Karen Atala presentó una denuncia ante la Comisión Interamericana de Derechos Humanos (CIDH) en contra del Estado de Chile (en razón de la competencia de ratio temporis y ratione materiae) por violaciones en sus derechos, al haberse fundado la determinación judicial en prejuicios discriminatorios en base a su orientación sexual, y al haberse agotado los recursos legales aplicables en Chile.

Dentro de los argumentos sostenidos por lo peticionarios se indica que los hechos determinan una violación a los Derechos Humanos no solo de Atala sino que también de sus hijas, especialmente "el derecho a la integridad personal (artículo 5.1); el derecho a las debidas garantías judiciales (artículo 8); la protección a la honra y la dignidad (artículo 11.1); la protección de la vida privada (artículo 11.2); la protección a la familia (artículos 17.1 y 17.4); los derechos del nińo (artículo 19); la igualdad ante la ley (artículo 24); y el derecho a la protección judicial (artículo 25), conjuntamente con la violación de las obligaciones de respetar los derechos y adoptar medidas consagradas en los artículos 1(1) y 2 previstos en la Convención Americana; y los artículos 2, 5, 9 (incisos 2 y 3), 12 y 16 de la Convención de las Naciones Unidas sobre los Derechos del Niño".

El Estado de Chile -en calidad de demandado- expresó que esta petición debería rechazarse, basándose en que se falló conforme a derecho, específicamente en lo que dice relación al cumplimiento del principio del interés superior de las niñas. Agregó, además, que los recursos legales internos de Chile no se encontraban agotados, debido a que la seńora Karen Atala podría haber interpuesto una nueva demanda de tuición.

La CIDH acogió la denuncia de la jueza chilena, concluyendo que ante el proceso y la decisión en el juicio de tuición, seguido en los Tribunales de Justicia de Chile (por casi dos ańos), tanto la señora Atala como sus tres hijas fueron víctimas de un sinnúmero de violaciones de derechos humanos que hasta la fecha persisten, en particular lo relacionado con el derecho a la igualdad, protegido por el artículo 24 de la Convención Americana de Derechos Humanos $(\mathrm{CADH})$, pues se aduce que la "distinción basada en la homosexualidad de la Sra. Atala careció de toda objetividad y razonabilidad en el juicio de tuición”. La Comisión agrega que el fallo de la principal magistratura chilena es "desproporcionado y limitante en el ejercicio de los derechos de los padres homosexuales, promoviendo que nunca puedan preservar la custodia de sus hijos, por concepciones estereotipadas de su habilidad para cuidarlos, y de crear un entorno saludable familiar para ellos". 


\section{1) ANÁlisis de la SENTENCIA DE LA CORTE INTERAMERICANA DE DERECHOS HUMANOS}

\subsection{1) Igualdad ante la ley y prohibición de discriminación arbitra- ria}

En primer lugar, cabe mencionar que el tribunal internacional distinguió entre las controversias en relación al proceso de tuición de las tres hijas de la jueza, y las relativas a la investigación disciplinaria aplicada a la magistrado.

En relación al proceso de tuición, el fallo reconstruyó la argumentación sostenida tanto por el Juzgado de Menores de Villarrica, que concedió la tuición provisional de las menores al padre, como por la Corte Suprema que resolvió concederle la tuición definitiva. Estas decisiones se fundaron en el principio del interés superior del nińo, el cual tiene sustento tanto en la Convención sobre los Derechos del Nińo como en la $\mathrm{CADH}$, y en los presuntos daños que las niñas habrían sufrido o podrían sufrir como consecuencia de la orientación sexual de su madre. Ahora bien, a diferencia de lo argumentado por el fallo de la Corte Suprema y del Juzgado de Menores de Villarrica, la Corte IDH razonó que "la determinación del interés superior del niño, en casos de cuidado y custodia de menores de edad se debe hacer a partir de la evaluación de los comportamientos parentales específicos y su impacto negativo en el bienestar y desarrollo del nińo según el caso, los dańos o riesgos reales y probados, y no especulativos o imaginarios. Por tanto, no pueden ser admisibles las especulaciones, presunciones, estereotipos o consideraciones generalizadas sobre características personales de los padres o preferencias culturales respecto a ciertos conceptos tradicionales de familia" (párrafo 109) ${ }^{1}$.

Para arribar a esta conclusión, el fallo argumentó, por primera vez en su evolución jurisprudencial, que la orientación sexual y la identidad de género son categorías protegidas por la Convención Americana de Derechos Humanos, bajo el término "otra condición social", del artículo 1.1 de dicho instrumento, por lo que la discriminación por orientación sexual

\footnotetext{
A pesar de que esta materia no será objeto de análisis en este comentario, la invocación de prejuicios sobre la homosexualidad y visiones restringidas en torno a la familia no ha estado exenta de crítica en la opinión pública en Chile. Solo a título ejemplar, véase el artículo de opinión del profesor Jorge Contesse, quien, además, representó a la jueza Atala ("Diversidad sexual y derechos humanos", en Ideas y Debates, La Tercera, 27/09/2010) y, más recientemente, la columna de opinión de Ascanio Cavallo titulada "Atala, la justicia y la mariposa", en La Tercera, sábado 31 de marzo de 2012, R8). Igualmente, cabe destacar la ausencia de elaboración interpretativa en torno al sentido de la expresión "los valores esenciales de la tradición chilena", en el artículo 22 de la Constitución, relativo a los deberes fundamentales de los chilenos, la cual naturalmente que tendría que ser observada a la luz de las profundas transformaciones de la sociedad chilena en los últimos treinta ańos.
} 
constituye una "categoría sospechosa", por lo que cualquier diferencia de trato basado en ella debe encontrarse justificada en el cumplimiento de algún fin legítimo y cumplir los demás requisitos del principio de proporcionalidad. En línea con esta argumentación, la Corte desestimó la argumentación esgrimida por la defensa del Estado de que la homosexualidad de la jueza no fue el principal argumento para la sentencia de la Corte Suprema, atendido que "basta con constatar que de manera explícita o implícita se tuvo en cuenta hasta cierto grado la orientación sexual de la persona para adoptar una determinada decisión" (párrafo 94). En este sentido, la Corte Suprema se sirvió de cuatro argumentos para avalar su tesis de que el interés superior de las menores ordenaría el otorgamiento de la tuición al padre: (i) el hecho de que la jueza, al ejercer su orientación sexual, "ha antepuesto sus propios intereses, postergando los de sus hijas"; (ii) la "eventual confusión de roles sexuales que puede producírseles [a las menores] por la carencia en el hogar de un padre de sexo masculino y su reemplazo por otra persona del género femenino"; (iii) por el potencial aislamiento y discriminación hacia las menores, derivada de su "entorno familiar excepcional se diferencia significativamente del que tienen sus compańeros de colegios y relaciones de la vecindad"; y (iv) la vulneración del "derecho preferente de las menores a vivir y desarrollarse en el seno de una familia estructurada normalmente y apreciada en el medio social, según el modelo tradicional”.

En relación al alegado privilegio a sus propios intereses que habría efectuado la jueza Atala al iniciar una convivencia con su pareja, en el hogar de crianza y cuidado de sus hijas, la Corte Interamericana sostuvo que "dentro de la prohibición de discriminación por orientación sexual se deben incluir, como derechos protegidos, las conductas en el ejercicio de la homosexualidad", en la medida en que estas son manifestaciones del derecho de todo ser humano a autodeterminarse y escoger libremente las opciones y circunstancias que le dan sentido a su vida. Una argumentación contraria, como la sostenida por el máximo tribunal chileno, contribuye también a la perpetuación de la discriminación en contra de la mujer, toda vez que exigirle a la madre que condicionara sus opciones de vida implica utilizar una concepción 'tradicional' sobre el rol social de las mujeres como madres, según el cual se espera socialmente que las mujeres lleven la responsabilidad principal en la crianza de sus hijos e hijas y que en pos de esto hubiera debido privilegiar la crianza de los niños y niñas renunciando a un aspecto esencial de su identidad" (párrafo 140).

Por otro lado, tampoco cabe admitir el argumento de la presunta confusión de roles de las menores, ya que "la eventual restricción de un derecho exige una fundamentación rigurosa y de mucho peso, invirtiéndose, además, la carga de la prueba, lo que significa que corresponde a la autoridad demostrar que su decisión no tenía un propósito ni un efecto 
discriminatorio" (párrafo 124), test estricto de análisis y sustentación de un daño concreto que la Corte Suprema no cumplió. En tal sentido, agrega la sentencia, "es necesario que en las decisiones judiciales sobre estos temas se definan de manera específica y concreta los elementos de conexidad y causalidad entre la conducta de la madre o el padre y el supuesto impacto en el desarrollo del nińo. De lo contrario, se corre el riesgo de fundamentar la decisión en un estereotipo" (párrafo 125).

A continuación, en relación a la supuesta discriminación social en contra de las menores por la orientación sexual de su madre, la Corte observó, en primer término, que se trató de un razonamiento abstracto y condicional, lo cual no puede servir de base para justificar una diferencia de trato, ya que "si bien es cierto que ciertas sociedades pueden ser intolerantes a condiciones como la raza, el sexo, la nacionalidad o la orientación sexual de una persona, los Estados no pueden utilizar esto como justificación para perpetuar tratos discriminatorios" (párrafo 119). En segundo término, en la determinación del interés superior de las menores, no cabe admitir la alegación de un posible estigma social derivado de la orientación sexual de la madre o padre, dado que acoger este razonamiento implicaría precisamente validar esa discriminación con el argumento de proteger el interés superior del menor $^{2}$, siendo el rol de los Estados precisamente "ayudar al avance social, de lo contrario se corre el grave riesgo de legitimar y consolidar distintas formas de discriminación violatorias de los derechos humanos" (párrafo 120).

Finalmente, en lo relativo al presunto derecho de las nińas a vivir en una familia "normal y tradicional" invocado por la Corte Suprema chilena, el fallo del organismo interamericano observa que la Convención Americana no establece un concepto cerrado de familia, ni define o protege un modelo "tradicional" de la misma. La apelación al concepto tradicional de familia repele el análisis de proporcionalidad de la diferencia de trato, toda vez que, como seńala el Tribunal Europeo de Derechos Humanos en el caso Karner vs. Austria, "El objetivo de proteger la familia en el sentido tradicional es más abstracto y una amplia variedad de medidas concretas pueden utilizarse para implementarlo [...] como es el caso cuando hay una diferencia de trato basada en el sexo o en la orientación sexual, el principio de proporcionalidad no solamente requiere que la medida sea, en principio, adecuada para el cumplimiento del objetivo

\footnotetext{
En tal sentido, resulta pertinente recordar lo seńalado por la Corte Suprema de Justicia de los Estados Unidos, en el caso Palmore v. Sidoti (de 25 de abril de 1984), en que seńaló que "la cuestión, sin embargo, es si la existencia de prejuicios privados y la posible vulneración que pueden causar, son consideraciones admisibles para el retiro de un nińo de la custodia de la madre natural. Tenemos pocas dificultades para concluir que no lo son. La Constitución no puede controlar esos prejuicios pero tampoco los puede tolerar. Las parcialidades particulares pueden estar fuera del alcance de la ley, pero la ley no puede, directa o indirectamente, permitir su aplicación”.
} 
adecuado. También se debe demostrar que era necesario excluir a ciertas categorías de personas para lograr ese objetivo" 3 .

\subsection{2) Derecho a la vida privada y protección de la vida familiar}

A continuación, el tribunal se hizo cargo del derecho a la vida privada de la denunciante, que comprende, entre otros ámbitos, la vida sexual y el derecho a establecer y desarrollar relaciones con otros seres humanos, concluyendo que "durante el proceso de tuición, a partir de una visión estereotipada sobre los alcances de la orientación sexual de la señora Atala, se generó una injerencia arbitraria en su vida privada, dado que la orientación sexual es parte de la intimidad de una persona y no tiene relevancia para analizar aspectos relacionados con la buena o mala paternidad o maternidad".

También el derecho a la protección a la vida familiar la Corte resolvió, en voto dividido, que "se había constituido un núcleo familiar" entre la Sra. Atala, su pareja, su hijo mayor de edad, y las tres hijas menores, y que la separación de dicha familia "constituyó una interferencia arbitraria en el derecho a la vida familiar", toda vez que se había constituido un núcleo familiar, el que, de forma arbitraria y prejuiciada, será desechado por el fallo de la Corte Suprema.

\subsection{3.) Otras consideraciones}

Finalmente, en lo relativo a las garantías judiciales en el proceso de tuición, el fallo dictaminó que no se vulneraron las garantías de independencia e imparcialidad de la jueza Atala toda vez que "no se aportaron elementos probatorios específicos para desvirtuar la presunción de imparcialidad subjetiva de los jueces". Sin embargo, la Corte estimó que la Corte Suprema de Chile vulneró el derecho de las niñas a ser oídas en el proceso judicial, ya que el máximo tribunal nacional "no había explicado en su sentencia cómo evaluó o tomó en cuenta las declaraciones y preferencias hechas por las menores de edad que constaban en el expediente".

Por último, en lo relativo a la investigación disciplinaria en contra de la jueza Atala desarrollada por la Corte de Apelaciones de Temuco, el fallo del organismo supranacional determinó que la consideración de la orientación sexual en dicha investigación era discriminatoria, toda vez que "la orientación sexual o su ejercicio no pueden constituir, bajo ninguna circunstancia, fundamento para llevar a cabo un proceso disciplinario, pues no existe relación alguna entre el correcto desempeño de la labor profesional de la persona y su orientación sexual", menos aún cuando 
el fundamento de la interferencia se hace radicar en la idea abstracta y vaga de la "imagen del poder judicial". En la misma línea, concluyó que la indagación relativa a estas circunstancias, constituye una vulneración del derecho a la vida privada de la jueza, al tiempo que sostuvo que "existieron prejuicios y estereotipos que fueron manifestados en el informe emitido por el ministro visitador, que demostraban que quienes realizaron y aprobaron dicho informe no fueron objetivos", lo que constituye una vulneración de la garantía de la imparcialidad subjetiva que protege a la señora Atala.

Como medidas de reparación, el fallo dispuso la publicación del resumen del fallo en el Diario Oficial y en un diario de amplia circulación nacional, la implementación de cursos y programas de educación y capacitación dirigidos a funcionarios públicos, en particular judiciales, y el pago de una indemnización por daño material (emergente) e inmaterial (moral) que allí se determina, entre otras medidas.

\section{3) COMENTARios}

(3.1.) En primer término, resulta a mi juicio esencial destacar el avance en el reconocimiento y configuración del principio de igualdad y la prohibición de discriminación arbitraria en la jurisprudencia sobre derechos fundamentales. La frecuente invocación de la igualdad por parte de los operadores jurídicos, ya sea ante el Tribunal Constitucional en sede de inaplicabilidad por inconstitucionalidad de preceptos legales, o ante la Corte Suprema en sede de acción de protección, ha dado lugar a una rica y nutrida jurisprudencia, a pesar de que claramente, y a la luz del fallo en comento, resta aún un largo camino por recorrer en materia de pleno respeto y promoción del derecho fundamental a la igualdad, sobre todo por parte de nuestros tribunales ordinarios de justicia.

A pesar de los más recientes avances en materia de jurisprudencia sobre la igualdad material, en particular a partir del fallo de inconstitucionalidad del artículo 38 ter de la Ley de Isapres (Rol No 1710-10) y del fallo de inaplicabilidad de la norma sobre la no imputación a la jornada laboral de las esperas entre turnos de los trabajadores del transporte interurbano (Rol No 1857-10), el caso Atala nos retrotrae a las clásicas problemáticas vinculadas a la igualdad formal, de trato o isonomía, vale decir, a la supresión de privilegios o discriminaciones arbitrarias de parte de la autoridad estatal a favor de ciertos grupos y/o en desmedro de otros. No se trata del establecimiento constitucional de una igualdad absoluta, sino de que "ha de aplicarse la ley en cada caso conforme a las diferencias constitutivas del mismo", considerando que "no es suficiente para concluir que ello [una diferenciación] es contrario a la Carta Fundamental, pues esta 
no prohíbe establecer diferencias, sino que hacerlo arbitrariamente; esto es, careciendo de fundamento razonable que pueda justificarlas" 4 .

El problema radica en establecer en qué casos este tratamiento diferenciado se ajusta al bloque de constitucionalidad y en qué casos no. Para esto, la jurisprudencia del TC ha delimitado el concepto de arbitrariedad, que se encuentra constitucionalmente prohibida no solo para la ley sino que para cualquier autoridad e incluso respecto de los particulares, sosteniendo que ello significa que la actuación no "responda a un propósito de hostilidad contra determinada persona o grupo de personas, o importe indebido favor o privilegio personal o de grupo" 5 . Así las cosas, para que los criterios de trato diferenciado sean constitucionalmente admisibles deben "sustentarse en presupuestos razonables y objetivos que los justifiquen, sin que, por tanto, queden completamente entregados al libre arbitrio del legislador"6. En este sentido, el Tribunal Constitucional, haciéndose eco de la jurisprudencia extranjera, particularmente de los Tribunales Constitucionales alemán y español, recurre frecuentemente al principio de proporcionalidad como dispositivo argumentativo para determinar la razonabilidad de un precepto legal, y con ello salvar las dudas de trato arbitrariamente discriminatorio. De esta forma, el principio de proporcionalidad se constituye en la metodología preferente de razonamiento jurídico que permitiría, de acuerdo a lo sostenido por la propia magistratura constitucional, resolver las dudas sobre la arbitrariedad de una determinada medida, y con ello delimitar el contenido del derecho a la igualdad en los casos concretos.

(4.2.) Más allá de la "tautológica"7 construcción de la igualdad por parte de nuestro Tribunal Constitucional, cabe pronunciarse sobre la consideración de la homosexualidad como una "categoría sospechosa". Al respecto, el fallo de la Corte IDH toma como punto de partida la consideración de la homosexualidad como "otra condición social", en los términos del artículo 1.1 de la $\mathrm{CADH}$, cuya invocación por parte del legislador o cualquier autoridad pública, hace incurrir a la medida en una vulneración de la igualdad ante la ley. Es lo que en derecho comparado, y

Tribunal Constitucional de Chile. Sentencia de 14 de septiembre de 2010, Rol No 1414. Acción de inaplicabilidad por inconstitucionalidad de Ingeniería y Construcción Pesada Limitada (INCOPESA) respecto del artículo 43, $N^{\circ} 1$, de la Ley $N^{\circ} 18.175$, que modificó y fijó el nuevo texto de la Ley de Quiebras. Además, véanse las sentencias Roles Nos 1200 y 1202.

5 En particular, ver las sentencias del Tribunal Constitucional Roles Nos 1204-09, 986-08 y 755-07.

6 Tribunal Constitucional de Chile. Sentencia de 28 de enero de 2010, Rol Nº 153509. Requerimiento de inaplicabilidad por inconstitucionalidad de María Rocio Zamorano Pérez respecto de la oración "cuando lo interpusiere el ministerio público" contenida en el inciso segundo del artículo 277 del Código Procesal Penal.

7 Correa Sutil, Jorge (2011). "Jurisprudencia del TC en materia de igualdad ante la ley. ¿Saliendo de la pura tautología?, en Javier Couso (ed.), Anuario de Derecho Público 2011. Santiago: Ediciones Universidad Diego Portales, pp. 96-126. 
también de forma algo tímida por parte de nuestro Tribunal Constitucio$\mathrm{nal}^{8}$, se denomina como una "categoría sospechosa", cuyo efecto jurídico radica en la alteración de la "presunción de constitucionalidad" a favor del legislador o la autoridad pública, y su reemplazo, en cambio, por el denominado "juicio estricto de igualdad". Para arribar a esta conclusión es menester efectuar una doble clarificación conceptual. En primer término, lo relativo a la definición y criterios para apreciar la pertenencia de un grupo a una cierta "categoría sospechosa", asunto particularmente complejo en nuestro sistema constitucional atendido que la Constitución no señala un listado de categorías sospechosas, como sí lo hacen otras cartas fundamentales como la espańola de 1978, e instrumentos internacionales tales como la propia Convención Americana de Derechos Humanos. De hecho, el artículo $19 \mathrm{~N}^{\circ} 2$ constitucional únicamente establece la diferenciación por sexo como categoría sospechosa, al señalar que "hombres y mujeres son iguales ante la ley". Sorprendentemente, sin embargo, el Tribunal Constitucional ha invertido el razonamiento que se derivaría de tal precepto. Así, en la sentencia Rol No 1710-10, de 6 de agosto de 2010, que declaró la inconstitucionalidad del artículo 38 ter de la Ley de Isapres, sostuvo que: "las diferencias fundadas en los criterios de la edad y del sexo de las personas, no son, en sí mismas, jurídicamente reprochables, ni tampoco prima facie arbitrarias, siempre que respondan a una fundamentación razonable". Al contrario, como señala Giménez, "en el juicio de 'mínimos' la legitimidad de la finalidad constitucional no supone un análisis demasiado inquisitivo: todo se limita comprobar que la finalidad de la norma no es manifiestamente contraria a la Constitución. (...) Sin embargo, en el juicio estricto el análisis de la finalidad de la diferencia de trato es el aspecto más importante de todos; el legislador está bajo sospecha y, en consecuencia, la presunción de legitimidad no existe" 9 . La distinción entre el juicio de mínimos y el juicio estricto, en consecuencia, radica en que el primero se sostiene sobre la base de la presunción de constitucionalidad de la medida, siendo el rol del juez constitucional más acotado, mientras que el segundo caso, que opera a partir

8 El Tribunal Constitucional no se ha pronunciado en forma expresa respecto de la conceptualización de las categorías sospechosa, salvo en el caso de los votos de minoría en dos sentencias recientes. El primero corresponde al voto de minoría de los ministros Vodanovic, Carmona y Viera-Gallo en la sentencia Rol $\mathrm{N}^{\circ} 1683-10$, de 4 de enero de 2011, relativo a un requerimiento de inaplicabilidad del artículo 365 del Código Penal, que sanciona el "acceso carnal" consentido entre un mayor de 18 ańos y un menor de 18 ańos y mayor de 14. El segundo caso corresponde al voto particular concurrente de los ministros Fernández, Carmona, Viera-Gallo y García, en la sentencia Rol N 1881-10, de 3 de noviembre de 2011, relativa a un requerimiento de inaplicabilidad del artículo 102 del Código Civil, en la medida en que restringe el matrimonio a un hombre y una mujer.

9 Giménez, David (2004). Juicio de igualdad y Tribunal Constitucional. Barcelona: Bosch, p. 282. 
del reconocimiento de la concurrencia de una categoría sospechosa, implica una mayor carga argumentativa de parte de quien formula la medida y, correlativamente, una revisión más profunda y rigurosa por parte del TC a este respecto. Ahora bien, el problema, a la luz de nuestra dogmática y jurisprudencia constitucional, es la falta de criterios claros y estables que permitan concretar qué grupos o categorías deberán ser objeto de un juicio estricto por parte del Tribunal Constitucional por estimarse que constituyen "categorías sospechosas", fuera del ya anunciado, a mi juicio, relativo a la distinción sobre la base del sexo de las personas. Para estos efectos, sería útil que el intérprete recurriera a los criterios establecidos por la jurisprudencia comparada e internacional, como herramienta interpretativa, adaptada en cualquier caso a las peculiaridades de nuestra teoría y dogmática constitucional ${ }^{10}$. De hecho, en mi opinión, una de las principales aportaciones teóricas del fallo de la Corte IDH en el caso Atala consiste precisamente en la justificación de la inclusión de la "orientación sexual" bajo el término "otra condición social" como una categoría sospechosa de aquellas que exigen un escrutinio estricto en el caso de eventuales diferencias de trato $^{11}$.

En segundo término, se presenta la dificultad relativa a la determinación del razonamiento jurídico que debiera operar bajo el denominado “juicio estricto de igualdad". Esta operación de razonamiento implica, en primer término, la revisión de la finalidad tenida a la vista en la diferencia de trato, la cual tiene que tener respaldo constitucional. Ahora bien, a fin de objetivar en mayor medida el juicio sobre la legitimidad constitucional de la finalidad perseguida por la distinción legislativa o de otra forma, el intérprete constitucional habrá de recurrir a un ejercicio de hermenéutica constitucional que le permita desentrańar la auténtica finalidad de la distinción y su contraste con algún principio o valor de relevancia constitucional, donde juegan un rol particularmente relevante los principios constitucionales plasmados en los capítulos introductorios de la Constitución $^{12}$. En nuestro sistema constitucional, estos principios y valores se encuentran recogidos en el Capítulo I de la Constitución, relativo a las bases de la institucionalidad, en particular en sus artículos $1^{\circ}, 4^{\circ}, 5^{\circ}, 6^{\circ}, 7^{\circ}$ y $8^{\circ}$. Establecido que una determinada diferenciación obedece a una finalidad constitucionalmente legítima, corresponde realizar el juicio de proporcionalidad de la medida, el cual ha sido aplicado por el TC chileno, sobre todo a partir del fallo que resolvió declarar inaplicable el artículo 595 del Código Orgánico de Tribunales, que establece la figura de los abogados de turno, por estimar que se infringe el principio de proporcionalidad,

Un buen punto de partida de este análisis puede encontrarse en el ya mencionado voto de minoría en la sentencia Rol N 1683-10, en el considerando decimoctavo.

$\mathrm{Al}$ respecto, véanse los párrafos 84 a 93 de la sentencia.

Giménez (2004) 284. 
"habida cuenta de que el turno gratuito solo se exige respecto de los abogados y no así en relación a otras profesiones que cumplen una función social", comparándolo con otras cargas en que sí se considera una remuneración por parte del Fisco, tales como el servicio militar o el actuar como vocal de mesa en un proceso electoral ${ }^{13}$. En cuanto al contenido del principio de proporcionalidad, el TC se ha remitido a los tres principios que formulara originalmente el Tribunal Constitucional Federal alemán, esto es, (i) el subprincipio de idoneidad o adecuación, en virtud del cual las medidas estatales han de ser idóneas para el logro de los fines que se persiguen, es decir, debe existir consistencia entre los medios empleados y los objetivos que se pretende satisfacer; (ii) el subprincipio de necesidad, que supone la valoración de alternativas de política pública, de manera que la escogida por el legislador sea la que menos afecte otros derechos fundamentales o bienes jurídico-constitucionales, en otras palabras, que no exista otra forma de conseguir esa finalidad que implique una limitación menor de los derechos fundamentales que la que se juzga; y (iii) el subprincipio de proporcionalidad en sentido estricto o ponderación, que exige un balance entre los efectos que la medida genera en los derechos e intereses de las personas, y los beneficios sociales que se obtienen, es decir, los medios utilizados no han de ser desproporcionados al fin que se persigue. En concreto, el TC ha sostenido que "si bien el legislador goza de discreción y de un amplio margen en la regulación de las relaciones sociales, debe cuidar que las restricciones al goce de los derechos que puedan resultar de tales regulaciones encuentren justificación en el logro de fines constitucionalmente legítimos, resulten razonablemente adecuadas o idóneas para alcanzar tales fines legítimos y sean -las mismas restricciones- proporcionales a los bienes que de ellas cabe esperar, resultando por ende tolerables a quienes las padezcan en razón de objetivos superiores o, al menos, equivalentes" 14 .

A partir de este esquema argumentativo, el Tribunal Constitucional contaría con parámetros de análisis para efectos de determinar si la medida legislativa o de otro tipo contraría el derecho fundamental a la igualdad y la prohibición de discriminación arbitraria. Ahora bien, aplicando este análisis a la sentencia de la Corte Suprema en el caso Atala, no se puede sino concordar con el fallo de la Corte IDH. En primer término,

13 Tribunal Constitucional de Chile. Sentencia de 31 de marzo de 2008, Rol No 755. Requerimiento de inaplicabilidad presentado por el abogado Sergio Toloza Rodríguez y el Presidente del Colegio de Abogados de Chile A.G., don Sergio Urrejola Monckeberg, en su representación, respecto del artículo 595 del Código Orgánico de Tribunales.

14 Tribunal Constitucional de Chile. Sentencia de 28 de mayo de 2009, Rol Nº 1204. Requerimiento de inaplicabilidad por inconstitucionalidad de Sociedad Constructora SIGMA Limitada respecto del artículo 1.891 del Código Civil. Esta misma idea ha sido desarrollada en las sentencias del Tribunal Constitucional Roles Nos 541, 1046, 1061, 1399/1469, entre otras. 
por cuanto la invocación de la condición homosexual de la jueza involucra una categoría sospechosa, sobre todo en consideración de que se discrimina a una persona sobre la base de su integración en un determinado grupo social, grupo que ha sufrido una intensa historia de discriminación y respecto del cual existen prejuicios sociales capaces de cercenar la posibilidad de defensa de sus intereses en el proceso político ${ }^{15}$. Al respecto, baste nada más recordar los fundamentos esgrimidos por algunos legisladores durante la discusión de la Ley $\mathrm{N}^{\circ} 19.617$, de 1999, que legitimó el delito de acceso carnal consentido entre un mayor de 18 años y un varón menor de 18 y mayor de 14 ańos, llegando algunos parlamentarios a considerar a la homosexualidad como "una lacra" y al acceso carnal entre personas del mismo sexo como "una conducta anormal desde el punto de vista de la naturaleza humana", cuya eventual despenalización "genera una tendencia, pues quienes la apoyen después deberán defender también el otorgamiento de la igualdad y el otorgamiento de derechos a las personas homosexuales" ${ }^{16}$. En el mismo sentido, cabe traer a colación lo señalado por la ONG ISFEM en su presentación al Tribunal Constitucional en el contexto del requerimiento de inaplicabilidad del artículo 102 del Código Civil, ya aludido, en el sentido de considerar a la homosexualidad como "una anomalía que consiste en la desviación de la atracción afectivo-sexual" y como una "patología curable"17. En segundo término, y entrando derechamente en el juicio estricto de igualdad de la diferencia de trato, cabe reconocer que, a pesar de la justificación constitucional de la diferencia de trato -la invocación del principio del interés superior del menor, reconocido en diversos instrumentos internacionales de derechos humanos-, no satisface la proporcionalidad de la medida, toda vez que la medida aplicada -pérdida de la tuición legal de las menores por parte de la madre- resulta demasiado gravosa en relación con el bienestar de las menores ${ }^{18}$, en particular a partir del subprincipio de ponderación, toda vez que de los antecedentes de la causa se desprendía que no existía una causa justificada como para revocar la tuición de la madre sobre las hijas, más allá de los prejuicios subjetivos de la mayoría de la sala falladora de la causa. Lo anterior, naturalmente, como fundamento adicional y comple-

15 Para un desarrollo de estas categorías en el derecho español sobre la base de la jurisprudencia constitucional de igualdad, véase GiMÉnEZ (2004) 247-9.

16 Véase al respecto el considerando decimotercero del voto de minoría de los Ministros Vodanovic, Carmona y Viera-Gallo en la sentencia Rol N ${ }^{\circ} 1683-10$.

17 Expresiones mencionadas en el voto de minoría del Ministro Vodanovic, aludido en el cuerpo de este comentario, en el considerando 3). Tribunal Constitucional de Chile. Sentencia de 3 de noviembre de 2011, sentencia Rol N ${ }^{\circ}$ 1881-10. Requerimiento de inaplicabilidad por inconstitucionalidad presentado por la Corte de Apelaciones de Santiago respecto del artículo 102 del Código Civil.

18 A idéntica conclusión arribó el Tribunal Europeo de Derechos Humanos, en el caso, ya citado, "Salgueiro da Silva v. Portugal", de 21 de diciembre de 1999. 
mentario al abordaje pormenorizado de las inconsistencias de la sentencia de la Corte Suprema, desde la perspectiva del juicio estricto de igualdad, que efectúa el fallo en comento. Hacia el futuro, cabe mencionar el interesante aporte del profesor Lovera, en el sentido de proponer criterios y reglas de razonamiento destinados a limitar la discrecionalidad judicial en casos en que esté involucrado el interés superior de los menores, apartándonos de jueces que deciden sobre la base de sus propias convicciones morales, sobre todo en cuanto a permitir y valorar la declaración de los nińos en el contexto de un juicio - principio de autonomía- y de prestar especial atención a la prueba pericial, que aumenta el estándar argumentativo del tribunal ${ }^{19}$.

(4.3.) Finalmente, este trascendental fallo contribuye también a enfatizar la necesidad de un fortalecimiento de la cultura de respeto, protección y promoción de los derechos fundamentales, de conformidad con lo dispuesto por el artículo $5^{\circ}$ de la Constitución, in fine, que dispone: "Es deber de los órganos del Estado respetar y promover tales derechos [los derechos esenciales que emanan de la naturaleza humana]". De esta forma, se debe recordar que el Poder Judicial, en particular la Corte Suprema, es un órgano del Estado vinculado por el mandato del artículo $5^{\circ}$ de la Constitución a partir del principio de supremacía constitucional del artículo $6^{\circ}$ de la Carta magna, por lo que debe no solo respetar los derechos humanos, sin también contribuir a su máxima promoción y desarrollo.

En este punto, cabe destacar la relevancia de la exigencia de fundamentación racional de las sentencias. La invocación de prejuicios sociales o visiones estereotipadas hacia un cierto grupo social, basadas en parámetros que no son intersubjetivamente aceptables, no puede servir de base para su ratificación o legitimación tácita por parte de los órganos del Estado. Estos se encuentran, al contrario, obligados a adoptar todas las medidas necesarias a fin de revertir esta tendencia y generar un cambio social orientado hacia un mayor respeto y reconocimiento de estas minorías excluidas o marginalizadas.

Como corolario, en mi opinión y más allá de la prudencia judicial y de la estabilidad de la jurisprudencia, en todo sistema constitucional es la ley el instrumento que garantiza generalidad y abstracción en el tratamiento jurídico que reciben las personas. En este sentido, más allá de la jurisprudencia, el articulado de la Constitución ha quedado superado, no por inútil, pues es una norma dúctil y abierta, sino porque hoy es necesario explicitar factores y criterios en materia de igualdad, cuestión que se puede hacer por dos vías: reformando la constitución para agregar lo que su texto no dice, o bien dictando una ley que regule el ejercicio del marionetas". En Justicia y Derechos del Niño, No 10, pp. 45-62. 
derecho a no ser discriminado arbitrariamente, estableciendo este tipo de elementos, camino por el cual aparentemente optó nuestro sistema político, a partir de la actual discusión del proyecto de ley antidiscriminación $^{20}$ que tiene precisamente por objeto delimitar aquellas variables que constituyen discriminación arbitraria, y de las cuales se derivan ciertas consecuencias para quienes cometan un acto de discriminación arbitraria, incluyéndose entre estas variables lo relativo a la orientación sexual, entre otras.

\section{BIBLIOGRAFÍA}

- Correa Sutil, Jorge (2011). "Jurisprudencia del TC en materia de igualdad ante la ley. ¿Saliendo de la pura tautología?, en Javier Couso (ed.), Anuario de Derecho Público 2011. Santiago: Ediciones Universidad Diego Portales, pp. 96-126.

- Giménez, David (2004). Juicio de igualdad y Tribunal Constitucional. Barcelona: Bosch.

- Lovera, Domingo (2007). "Razonamiento judicial y derechos del niño: de ventrílocuos y marionetas". En Justicia y Derechos del Niño, No 10 , pp. 45-62.

- Tribunal Constitucional De Chile. Sentencia de 14 de septiembre de 2010, Rol N ${ }^{\circ}$ 1414. Acción de inaplicabilidad por inconstitucionalidad de Ingeniería y Construcción Pesada Limitada (INCOPESA) respecto del artículo 43, $N^{\circ} 1$, de la Ley $N^{\circ} 18.175$, que modificó y fijó el nuevo texto de la Ley de Quiebras. Además, véanse las sentencias Roles Nos 1200 y 1202.

- Tribunal Constitucional De Chile. Sentencia de 28 de enero de 2010, Rol No 1535-09. Requerimiento de inaplicabilidad por inconstitucionalidad de María Rocio Zamorano Pérez respecto de la oración "cuando lo interpusiere el ministerio público" contenida en el inciso segundo del artículo 277 del Código Procesal Penal.

- Tribunal Constitucional De Chile. Sentencia de 31 de marzo de 2008, Rol $\mathrm{N}^{\circ}$ 755. Requerimiento de inaplicabilidad presentado por el abogado Sergio Toloza Rodríguez y el Presidente del Colegio de Abogados de Chile A.G., don Sergio Urrejola Monckeberg, en su representación, respecto del artículo 595 del Código Orgánico de Tribunales.

- Tribunal Constitucional De Chile. Sentencia de 28 de mayo de 2009, Rol $\mathrm{N}^{\circ}$ 1204. Requerimiento de inaplicabilidad por

20 Boletín $\mathrm{N}^{\circ}$ 3815-07, iniciado por mensaje de la ex Presidenta Michelle Bachelet, actualmente en discusión en Comisión Mixta. 
inconstitucionalidad de Sociedad Constructora SIGMA Limitada respecto del artículo 1.891 del Código Civil. Esta misma idea ha sido desarrollada en las sentencias del Tribunal Constitucional Roles Nos $541,1046,1061,1399 / 1469$, entre otras.

- Tribunal Constitucional De Chile. Sentencia de 3 de noviembre de 2011, sentencia Rol No 1881-10. Requerimiento de inaplicabilidad por inconstitucionalidad presentado por la Corte de Apelaciones de Santiago respecto del artículo 102 del Código Civil.

- Tribunal Europeo De Derechos Humanos, caso "Salgueiro da Silva v. Portugal", de 21 de diciembre de 1999. 